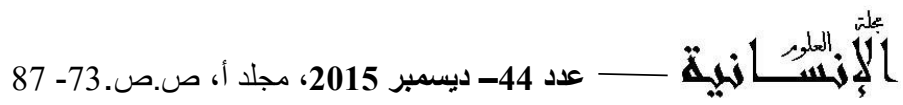

\title{
دور صناديق التحوط في الأسواق المالية
}

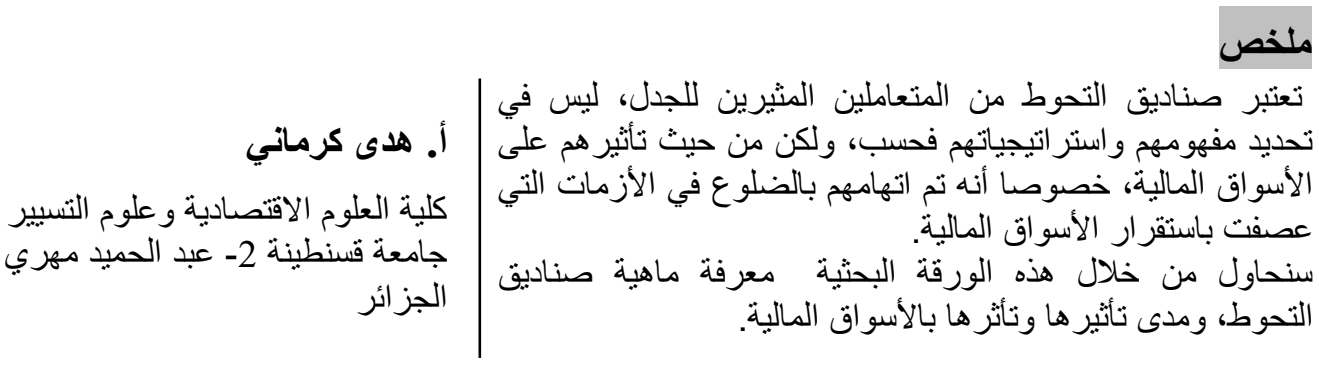

شئهدث صناديق التحوط تطور ا ملحوظا خلال

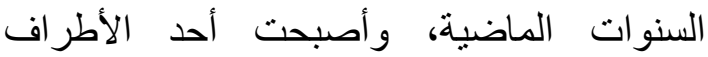

الأساسية في الأسواق المالية.

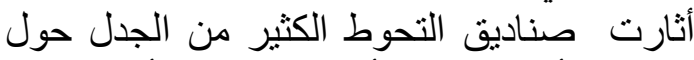

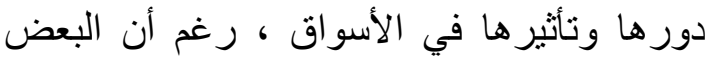

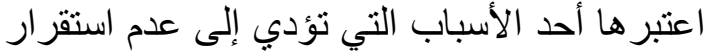

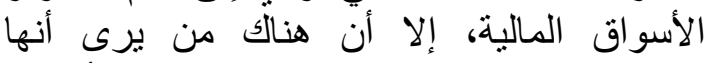

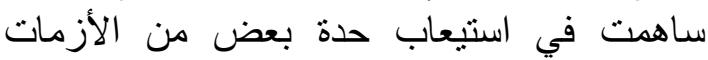

المالية التي عرفتها مختلف البلدان.

Abstract

Hedge Funds the controversial dealers, not only in identifying their concept and strategy, but

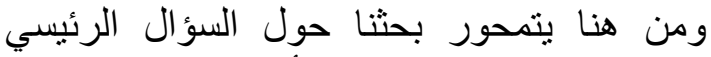
regarding their influence on the

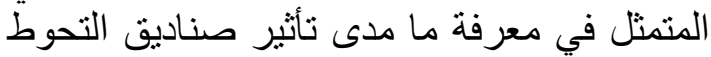
على استقرار الأسواق المالية؟ Financial Markets ;especially, for they have been accused of involvement of crises, that have

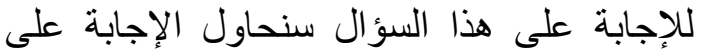
disturbed the stability of the التساؤلات الفر عية التالية: ما ماهية صناديث التحوط؟ Financial Markets.

This paper try to explain the concept of Hedge Funds, and ما دورها في ضبط أو أو زعزعة استقرار الأسواق what extent their influence and how they affected the Financial Markets. 


\section{I}

تعد صناديق التحوط وجها من أوجه التطور المالي، تعتمد على تقنيات تسيير

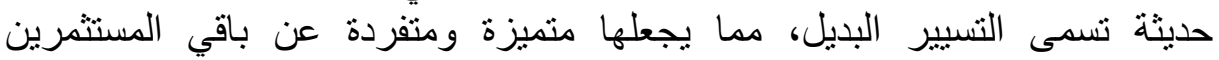
المؤسساتيين.

لقد أجمع الاقتصاديون على صعوبة إعطاء تعريف دقيق لصناديق التحوط (1)، لنظر الخصوصيتها، و عدم شفافيتها.

سنورد فيما يلي جملة من التعاريف التي حاولت الإحاطة بمفهومها.

يعرفها رئيس سلطة الخدمات المالية (FSA) Financial Services Authority باعنة

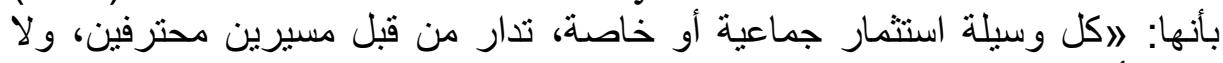
تفتح رأسمالها للجمهور الوسلة اسعها: (2).

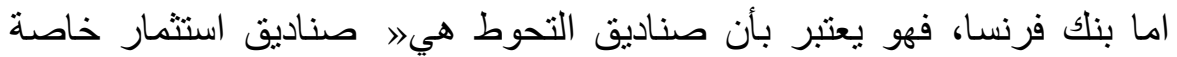
تستثر في وسائل قابلة للتفاوض، ونثان وتستعمل أثر الرفع المالي، وضئ وغالبا مالا تخضع

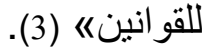

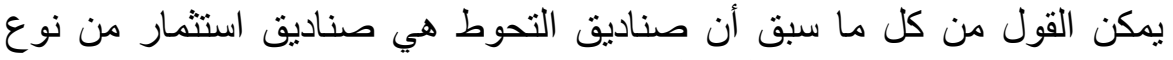

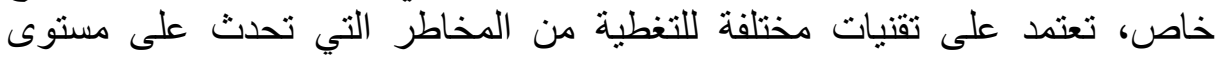

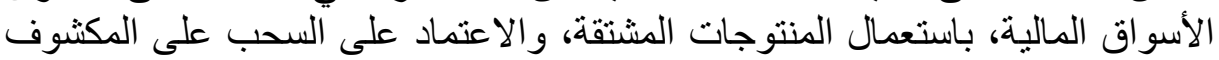
والرفع المالي.

تبحث صناديق التحوط عن مردودية مطلقة غير مرتبطة بمؤشرات أداء السوق، مما يجعلها في منأى عن تطاير و لا استقرار السون ماند المالي. وقد ازدادت أهميتها وتطور حجمها و عددها في السنوات الماضية، مما يؤكد

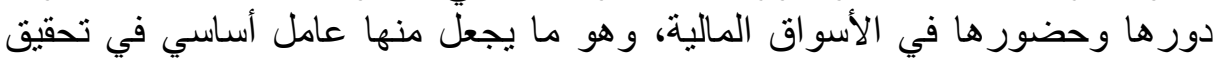
استقرار أو لا استقرار الأسواق المالية.

توضح الأشكال التالية التطور الكبير لصناديق التحوط خلال السنوات الماضية. شكل1 :عدد صناديق التحوط في العالم 


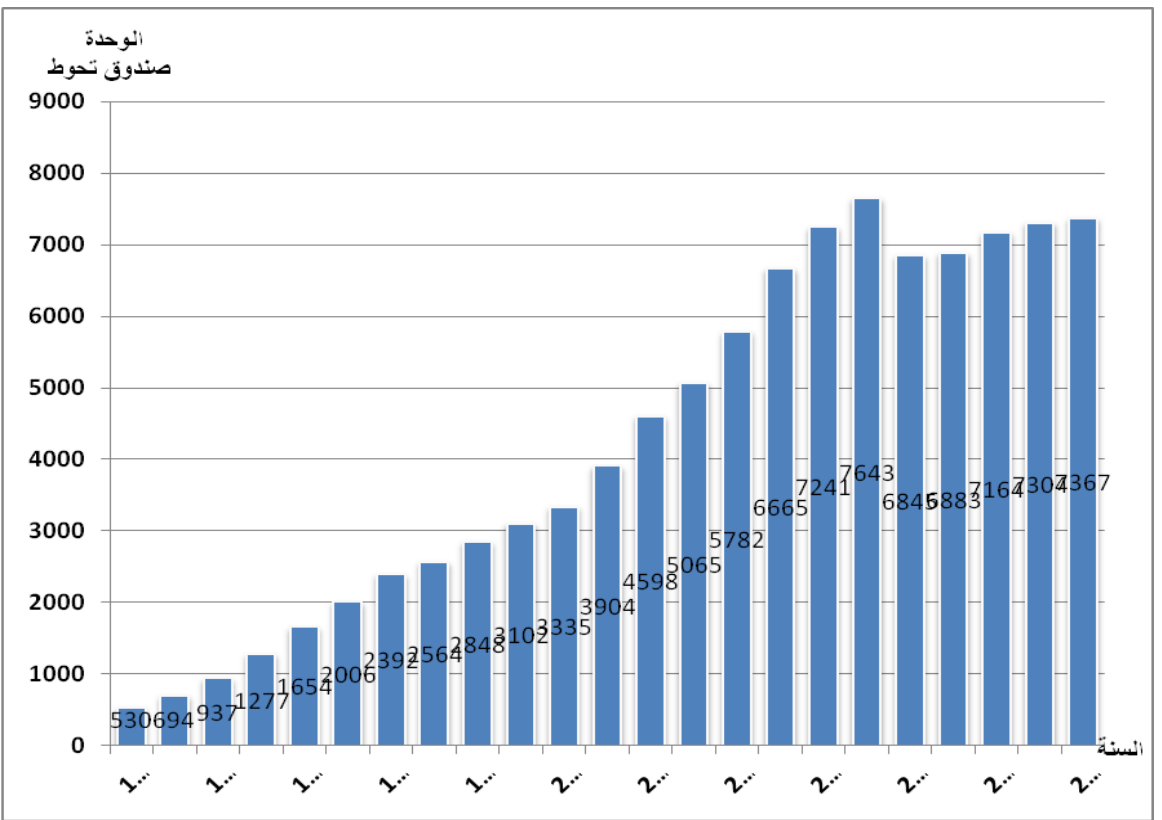

Source : www.hedgefundresearch.com

شكل2 حجم الأصول المسيرة من طرف صناديق التحوط 1990-2012

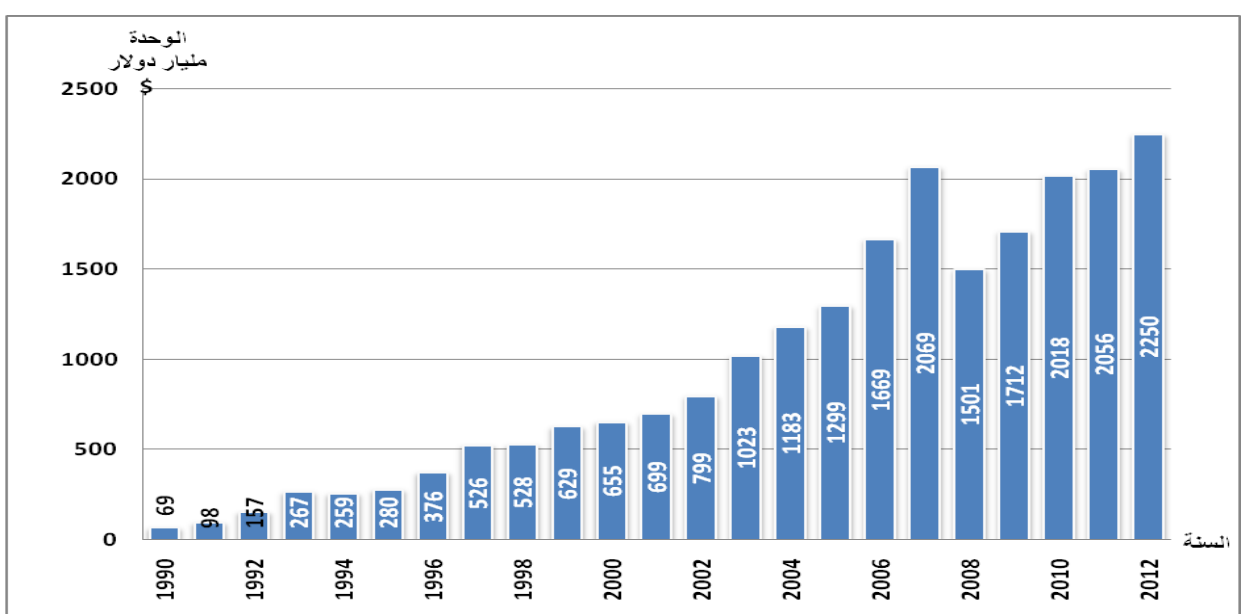

Source : www.hedgefundresearch.com

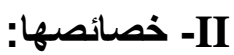

تتميز صناديق التحوط بخصائص تميزها عن باقي المستثمرين المؤسساتيين،حيث 
إن در اسة هذه الخصائص بإمكانه أن يكون نقطة الانطلاق، لتحديد كيفية تأثنير ها على الأسو اق المالية.

يمكن ذكر بعض خصائصها كما يلي (4): ـلا تخضع صناديق التحوط لأية قوانين خاصة بالإشهار أو التسجيل -تتمركز غالبا أنشطتها في الواحات الضريبية -تعمل على تتويع حو افظها تنويعها كبير ا، ولا يرتبط عملها بمؤشر معين

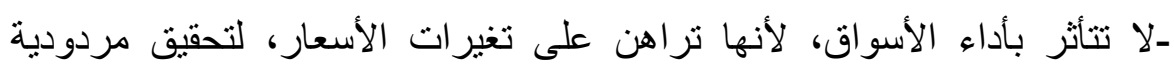
مطلقة

-تستعمل أثر الرفع المالي والبيع على المكثوف في تعاملاتها -لا تفتح رأسمالها إلا لعدد محدد ومميز من العملاء، خصوصا المستئمرين المؤسساتيين.

من الملاحظ أن عمليات صناديق التحوط تتميز باللاشفافية، ولها حرية كبيرة في

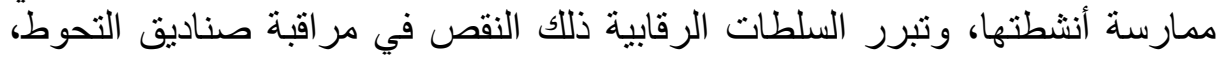

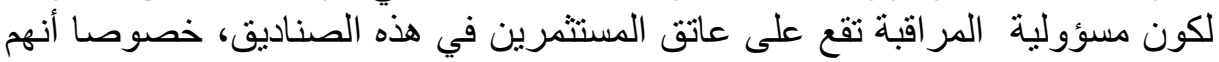
يتمتعون بالخبرة في الإدارة ولئ التسيير.

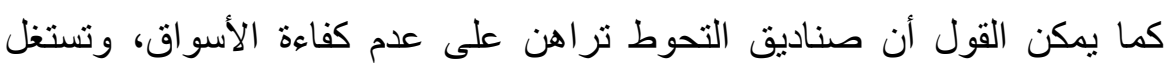

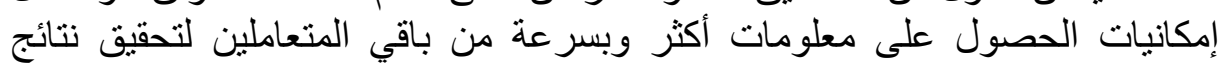
إيجابية تفوق ما يحققه باقي المنافسين.

\section{التقتيات التي تستخدمها صناديق التحوط:}

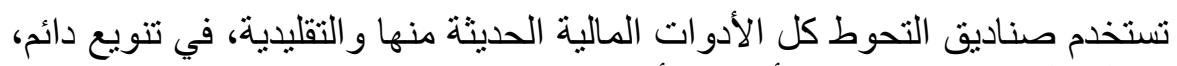

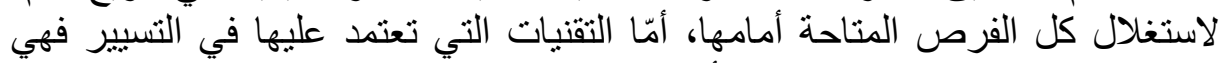

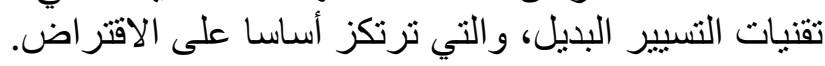

تتمثل هذه الوسائل فيما يلي (5):

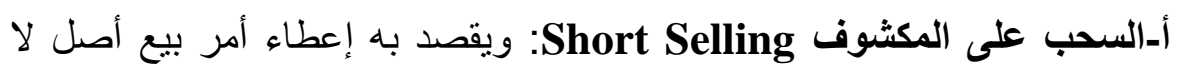

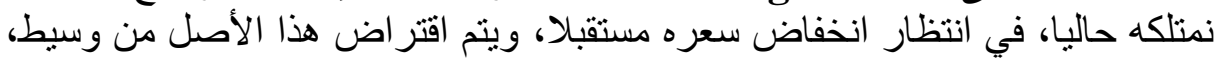

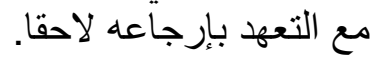
ب-الرفع المالي Leverage: يقصد به اقتراض الأموال من الغير لتمويل الاحتياجات الخاصةٌ بالاستثمار .

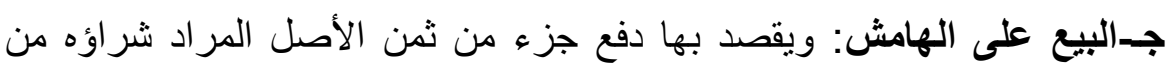
أموال المستثر الخاصة، ودفع الجزء الباقي عن طريق الاقتراض. 
تعد هذه التقنيات من أهم الوسائل التي تستخدمها صناديق التحوط، بالإضافة إلى الى التى

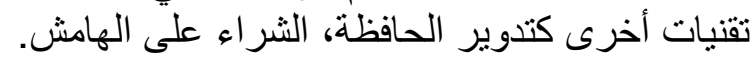

باستخدام هذه التقنيات تقحم صناديق التحوط، كل مقرضيها في كل المخاطر التي

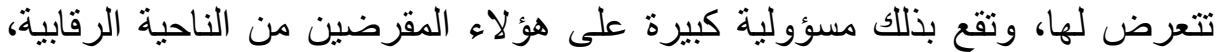

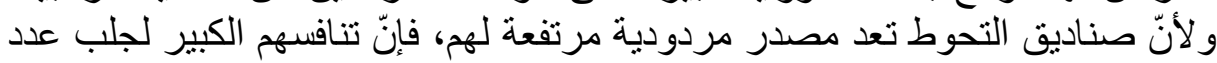

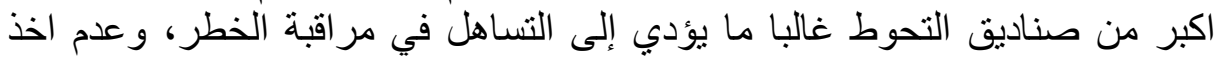

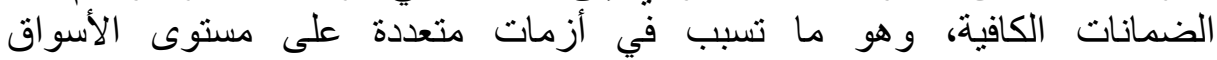
المالية ،حسب رأي معظم الباحثين و المهتمين.

\section{استراتيجيات صناديق التحوط:-IV}

يمكن تصنيف استر اتيجيات صناديق التحوط في ثناث مجموعات أساسية وهي (6):

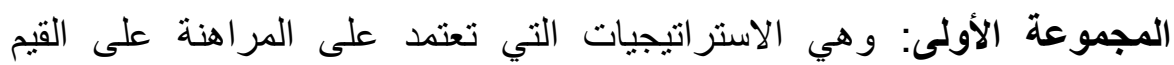

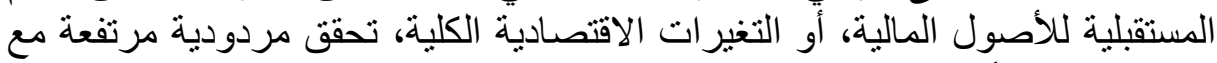

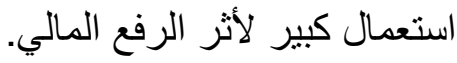

المجموعة الثانية: تضم الصناديق التي تعتمد على استر اتيجيات التحكيم، باستغلال

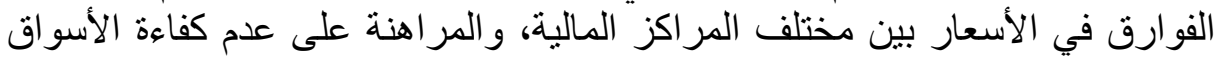

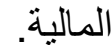

المجموعة الثالثة: تقوم على استخلال الظروف الخاصة للمؤسسة كقيام هذه

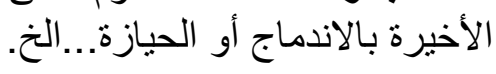

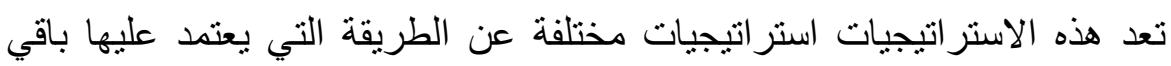

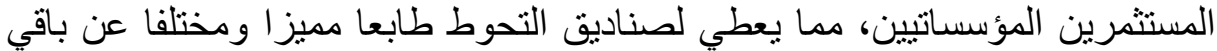

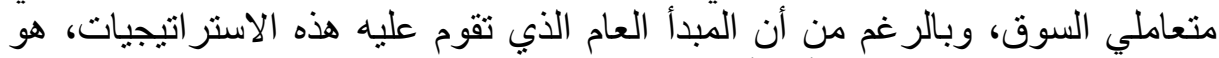

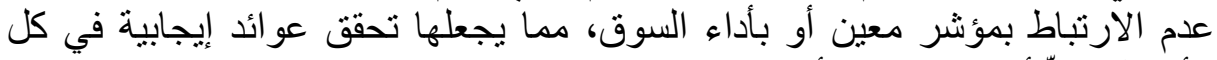

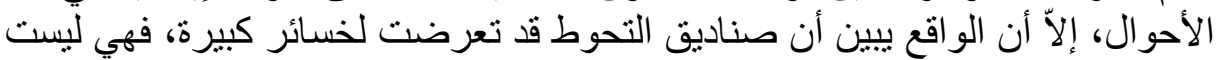

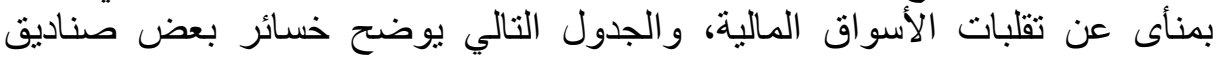

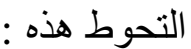

\section{جدول 1: الخسائر التي منيث بها بعض صناديق التحوط:}

\begin{tabular}{|c|c|c|c|}
\hline طبيعة المشكلة & 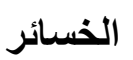 & السنة & الصندوق \\
\hline ارتباط استر اتيجيته بأسعار الطاقة & 6400 & 2006 & Amaranth \\
\hline مبالغة في استخدام أثر الرفع & 3600 & 1998 & Long term capital \\
\hline
\end{tabular}


هدى كرماني

\begin{tabular}{|c|c|c|c|}
\hline الروسية، خلال أزمة الديون & & & \\
\hline رهان مشبوه فيه على عملة الين. & 2600 & 2000 & Tiger management \\
\hline خو التكنولوئر كبيرة في أسواق الانترنت & 5000 & 2000 & Soros funds \\
\hline ت تلاعب & 700 & 2001 & Lipper \\
\hline تأثر بانهيار عملة الباث التايلندي & 125 & 1997 & Global system fund \\
\hline
\end{tabular}

Source: Alexander Ineichen «The myth. of Hedge funds », cité par: Roger Ferguson, David Laster," Hedge funds et risque systémique", Revue de la stabilité financière, $\mathrm{N}^{\circ} 10$, Avril, 2007, P54.

\section{V ت تأثير صناديق التحوط على استقرار الأسواق المالية:}

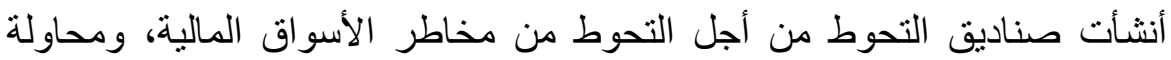
تحييد هذه المخاطر، إلا أن الملاحظ أن العديد منها تحول إلى مضارب الته مستغل

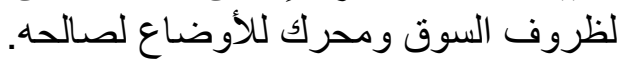

لمعرفة الدور الذي تقوم به هذه الصناديق، سنقوم بدر اسة النقاط التالية:

$$
\text { - دور صناديق التحوط في الأزمة المالية }
$$

ـ درجة الخطر المرتبطة بعمل صناديق التحوط

ـ تأثنير صناديق التحوط على المؤسسات التي تستثمر فيها أمو الها.

\section{أـ دور صناديق التحوط في الأزمات المالية : \\ أ-1-صناديق التحوط والأزمة النقدية الأوروبية :}

عرف النظام النقدي الأوروبي تراجعا في أسعار الصرف خلال سنتي 1992

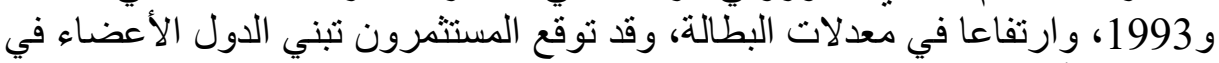

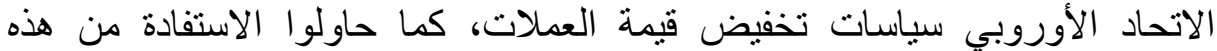

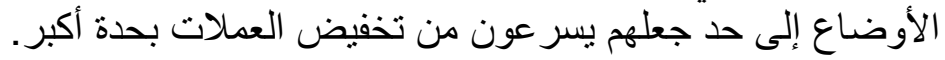

لقد استغلت صناديق التحوط الظروف التي مرّ بها النظام النقدي الأوروبي، وكان لصندوق "Quantum" لصاحبه "جورج سورس"، دور كبئ الفير خلافل أزمة 1992، 
بحيث راهن على انخفاض الجنيه الاسترليني، وتسبب في تغيرات كبيرة للعملة

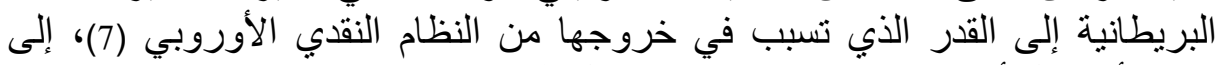
درجة أنه يقال أن "جورج سورس" هو الرجل الذي تسبب في تفجير بنك انجلتر ا. بالرغم من محاولات بنك انجلترا تدارك الوضع إلا أنّ قيام صندوق التحون التحوط

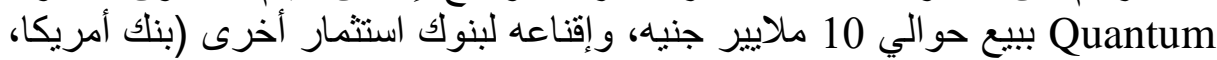

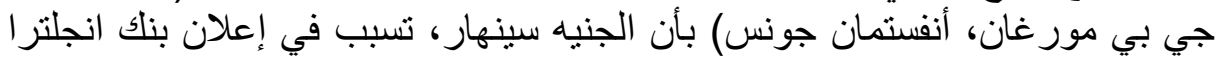

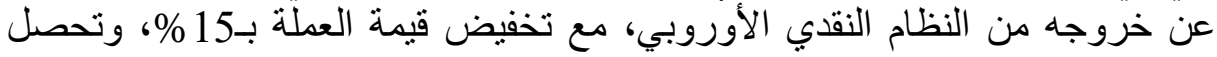

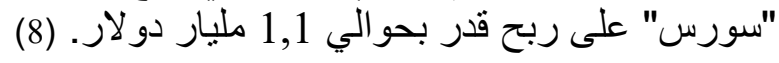

\section{أ-2- دور صناديق التحوط في أزمة جنوب شرق آسيا:}

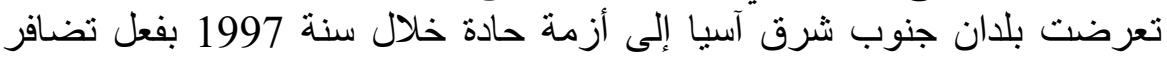

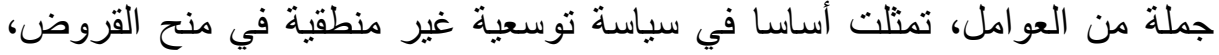
بمعدلات منخفضة، ودون تونة تمني الحذر.

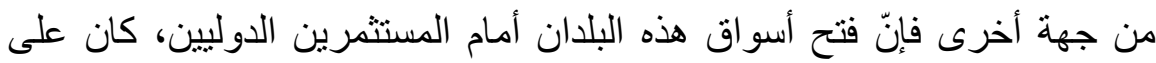
حساب الدارة الحقيقية، مما تسبب في عدم توازن في فين البل القطان أماعين الحقيقي والنقدي. كما عرفت العديد من كبريات المؤسسات مشاكل مالية أدت إلى تصفية معظمها، الأية

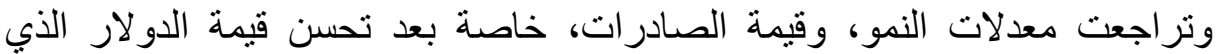
كانت العديد من دول جنوب شرلات وق آسيا تربط عملاتها به.

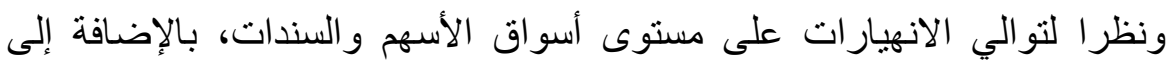

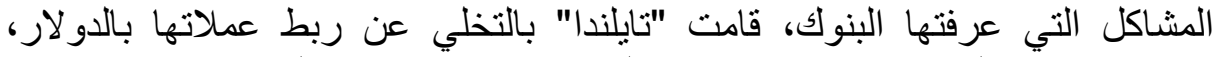

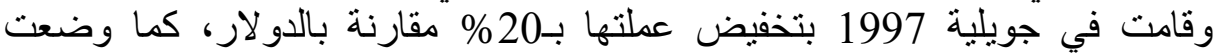
تايلندا تحت وصاية صندوق النقد الدولي، وحصلت على إعانة بمقدار 40 مليار دولار لار كلار

في أوت 1997.

اتهم الوزير الأول الماليزي صر احة صناديق التحوط، بأنّها السبب في الأزمة التي

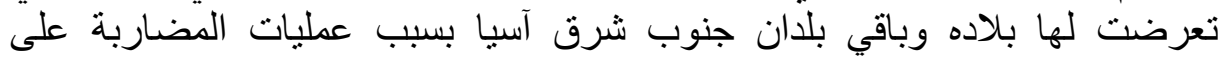
عملاتها. (10)

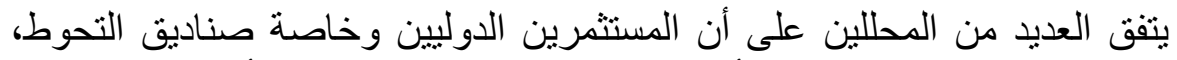

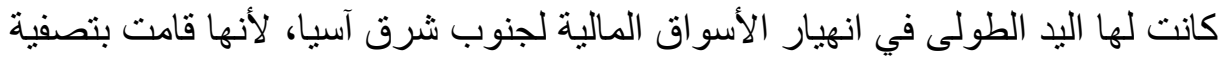

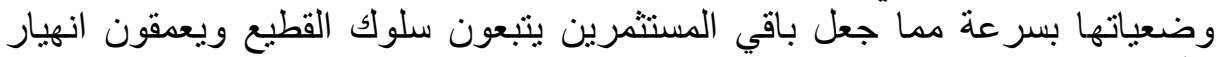

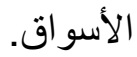

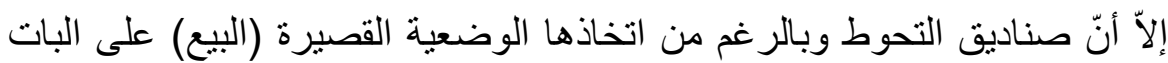

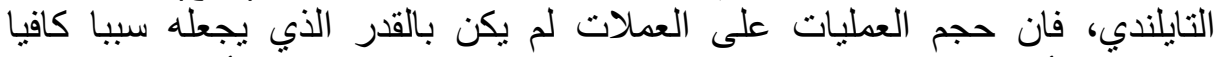

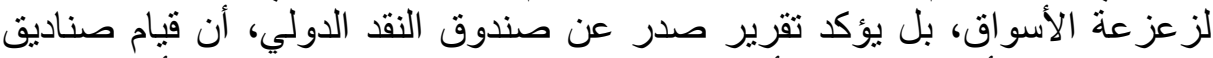

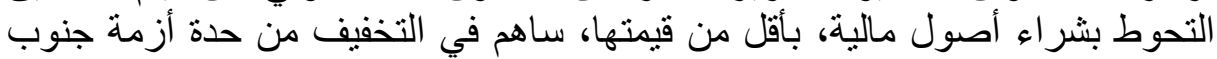


شرق آسيا، والعودة السريعة للتوازن (11)، وفي تقرير أخر لصندوق النقد الدولي أعد

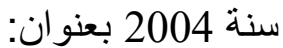

Hedge Funds and recent emerging market, currency Crisis, Global financial stability report.

تم التوصل إلى أن صناديق التحوط لعبت دور ا إيجابيا في الأزمات النقدية للبرازيل

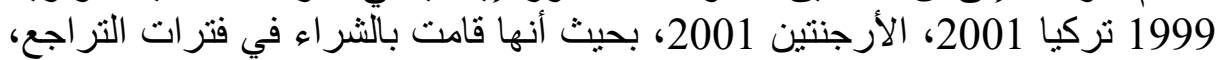

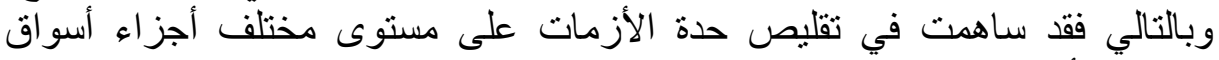

\section{أ-3- دور صناديق التحوط في أزمة الرهن العقاري:}

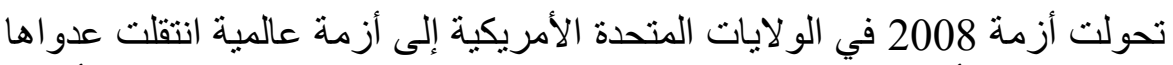

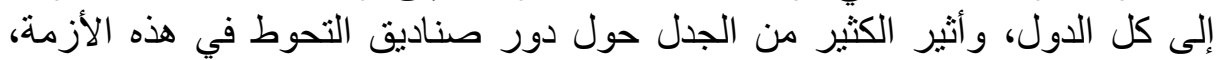

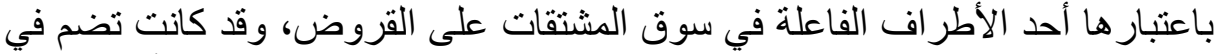

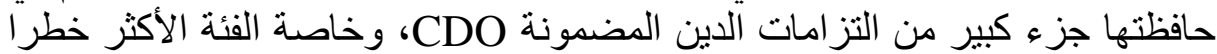
مقارنة بباقي المستثمرين كما يوضحه المات الجدول المضين التالي:

\section{جدول 2: مشتروا التزامات الدين المضمونة CDO}

\begin{tabular}{|c|c|c|c|c|}
\hline الأصسول & $\begin{array}{c}\text { البنوك } \\
\%\end{array}$ & صناديق التحوط & شأتركات & $\begin{array}{l}\text { شرائح } \\
\text { CDO }\end{array}$ \\
\hline 5,8 & 14,5 & 12,1 & 6,9 & AAA \\
\hline 4 & 3,5 & 4 & 1,2 & $\mathrm{Aa}$ \\
\hline 2,9 & 1,4 & 4,6 & 0,3 & A \\
\hline 0,3 & 0,3 & 4,3 & 0,6 & $\mathrm{BBB}$ \\
\hline 0,3 & 0,3 & 2,3 & 00 & $\mathrm{BB}$ \\
\hline 1,7 & 4,9 & 19,1 & 0,9 & الأسهم السائلة \\
\hline 18,8 & 24,9 & 46,5 & 9,8 & المجموع\%\% \\
\hline 564 & 746 & 1396 & 295 & مليون دو لار \\
\hline
\end{tabular}

Source: Blundel -Wi Gnall,"Structured products: Implications for financial Markets", OECD Financial Market trends, N93, Vol, 2007, P45.

لقد كان بحوزة صناديق التحوط نصف القيمة تقريبا من منتجات (CDO) التي التي

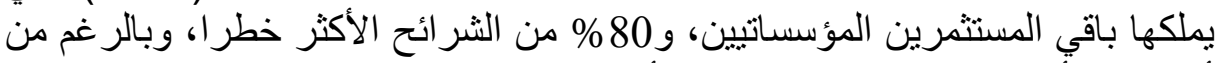

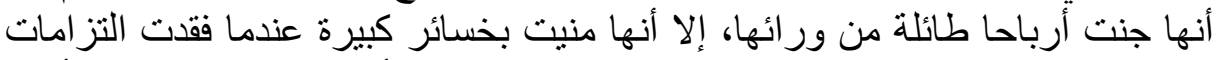

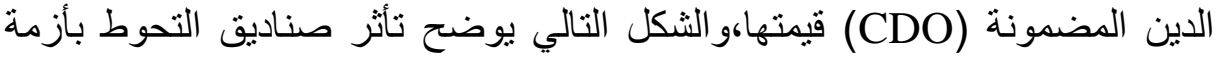


شكل ( 3) حجم صناديق التحوط خلال أزمة الرهن العقاري

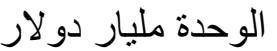

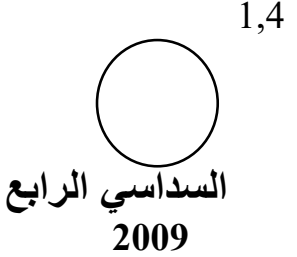

1,4
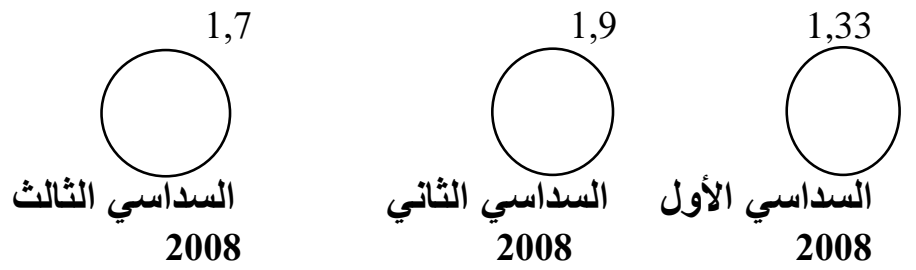

Source : www.Fimmac. Blogs pot.com

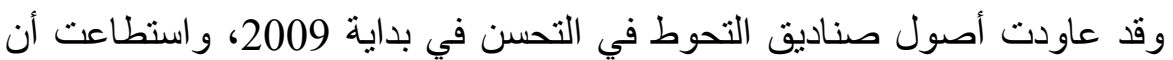

تحقق أرباحا بلغت 55,5 مليار دو لار، و وهي أكبر أرباح تحققها منذ 2007. (12)

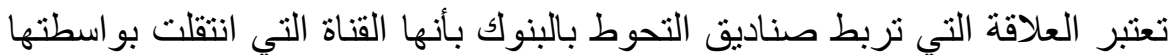

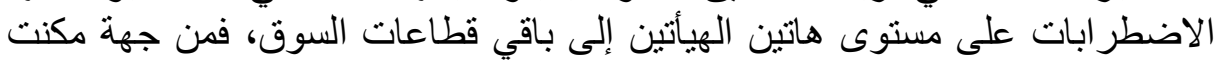

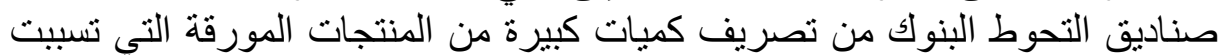

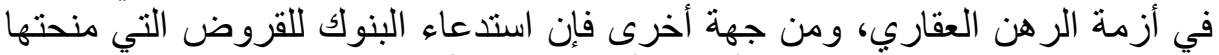

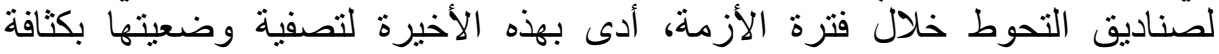

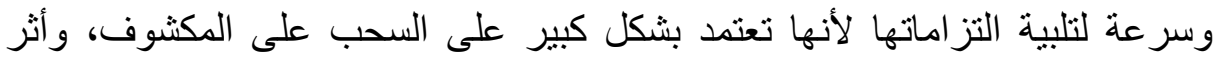

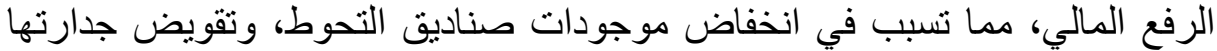
الااتثمانية، كما أفلس العديد منها وانتشرت أنثار الأزمة من مكان لآخر.

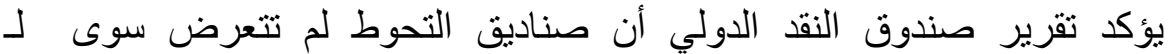

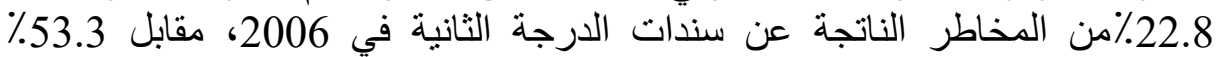

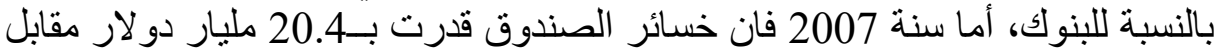

28.8 مليار دولار بالنسبة للبنوك. (13)

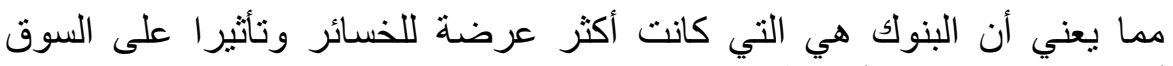
المالي مقارنة بصناديق التحوط.

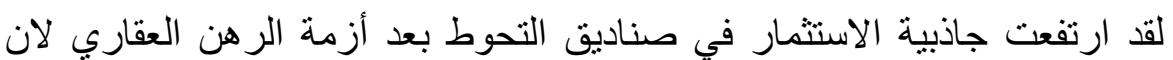

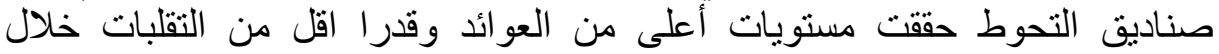
الأزمات المالية مقارنة بفئات الاستثمار الأخرى. (14)

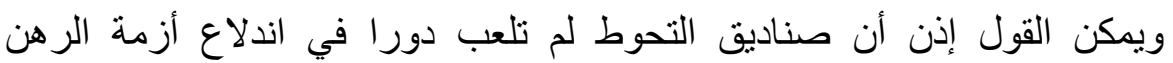

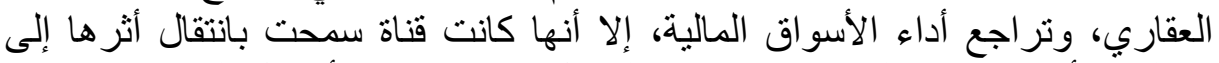

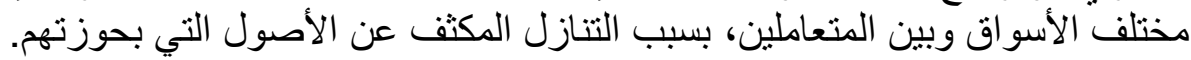

ب-درجة الخطر المتعلقة بنشاط صناديق التحوط: 
يعتقد البعض بأنّ الاستثمار في صناديق التحوط، يؤثر سلبا على السوق المالي،

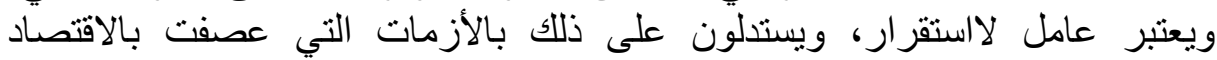

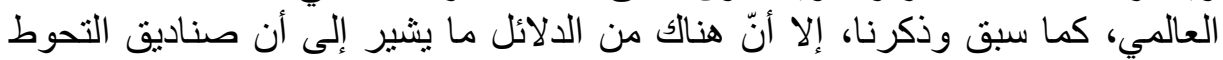

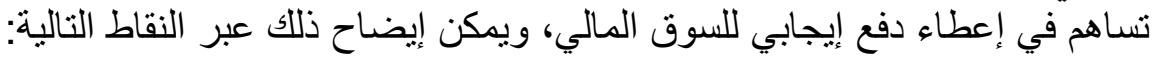
-يستخدم معامل "شارب" "sharpe" لقياس كفاءة وفعالية صناديق التحوط مقارنة إعنة بمختلف الأصول الممكن الاستثمار فيها.

يعبر معامل "شارب" عن العلاقة بين المردودية المرتفعة من جهة، و المردودية دون مخاطرة من جهة أخرى. لبعل

يمثل الجدول التالي قيمة هذا المعامل بالنسبة لصناديق التحوط، خلال فترة فرة معينة مقارنة بباقي المتعاملين حسب المعلو هالئ المعات المتاحة.

جدول رقم (3) معامل شارب لصناديق التحوط

\begin{tabular}{|c|c|c|}
\hline 2003 - نوفمبر 2007 & 2003- جوان 2007 & معامل شـارب \\
\hline 2,25 & 2,39 & صناديق التحوط \\
\hline 0,1 & $-0,04$ & 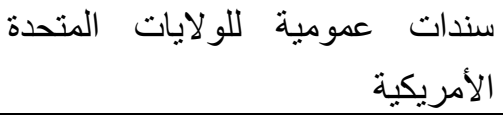 \\
\hline 2,37 & 2,2 & أسهر الأسو اق الناشئة \\
\hline
\end{tabular}

Source : Merril Lynch, Natixis Report, 2008 ;P15:

يتميز الاستثمار في صناديق التحوط بمعامل "شارب" مرتفع، وهو ما مانعني

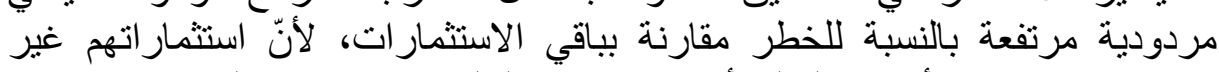

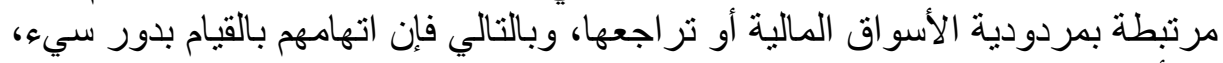
هو أمر غير صحيح.

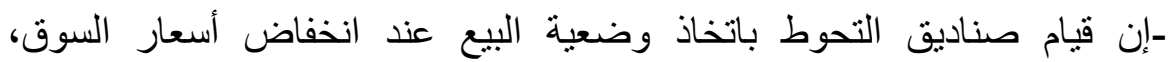

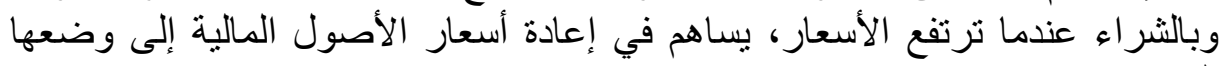
التوازني.

لكن لا يحدث ذللك في كل الحالات، إذ أن قيام صناديق التحوط، بتصفية وضعياتها

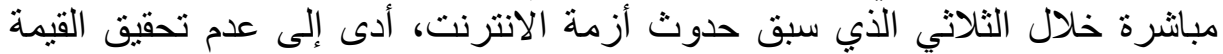

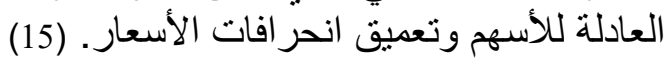

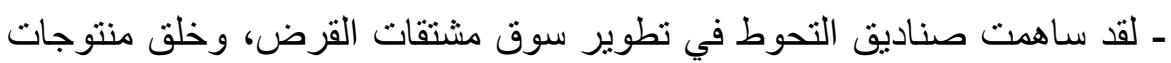

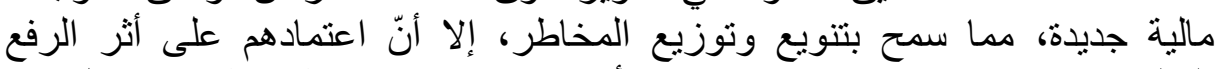

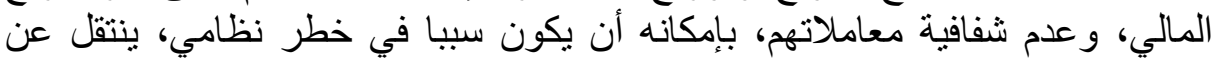


طريق قناة البنوك، وباقي المستثرين إلى كل أجزاء الأسواق، ويتسبب في نشويه نظام الأسعار.

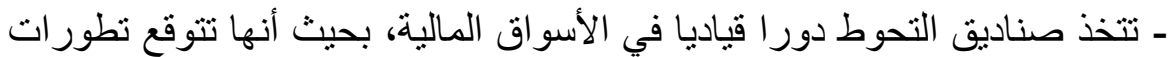
الأسعار ، وتتبنى استر اتيجيات معينة بناء على ذللك، وبالتالي فهي لا تتبع ما يطلق على اليه

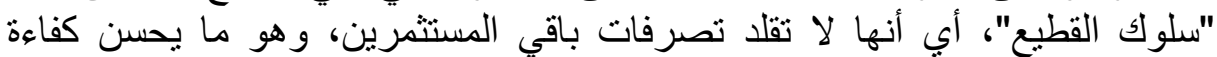

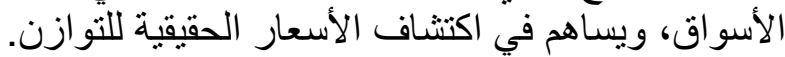

- تساهم صناديق التحوط في سيولة السوق المالي خاصة على على مستوى أسواق التهات

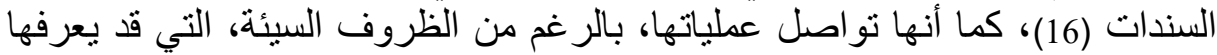

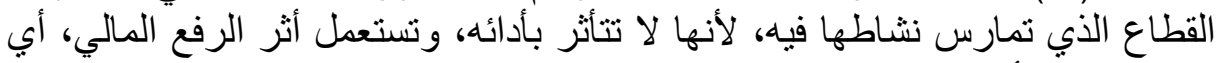

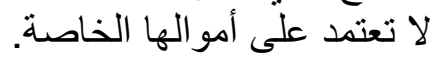

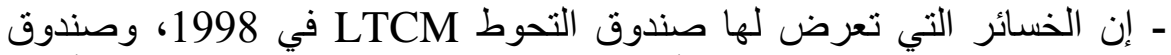
Amaranth في 2006، لم يكن لها تأثثير على باقي صناديق التحوط، ولم ينتقل أثرها

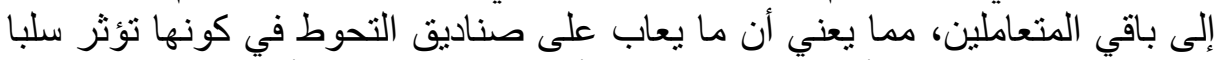

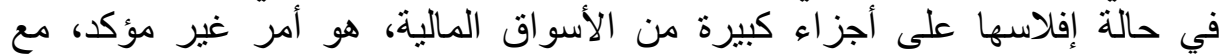
الإشارة إلى أنه تم إنقاذ صندوق LTCM من طرف البناء الإنك الاحتياطي الفدر الي تخوفا

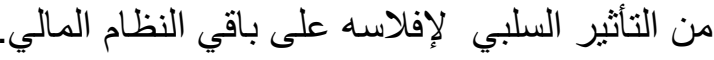

\section{ج- دور صناديق التحوط في تحديا قيمة المؤسسات :}

توصلت در اسة نشرت من قبل Warton School سنة 2006 ، إلى أن صناديق

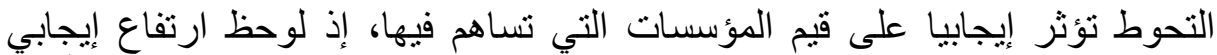

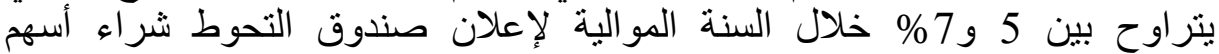

المؤسسة، كما ترتفع الأرباح بنسبة 11 11\% دون نراجع. (17)

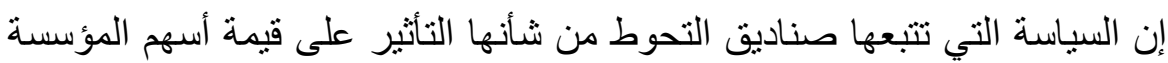

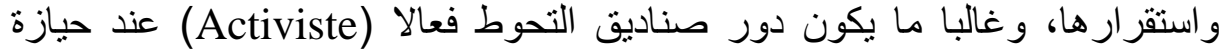

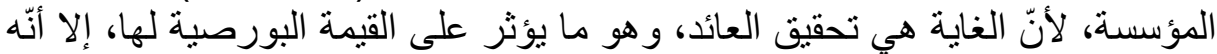

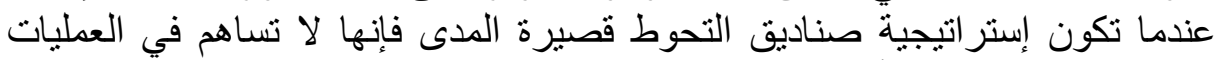

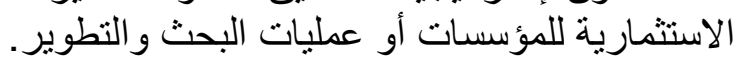

الخاتمة

تؤثر صناديق التحوط على ديناميكية الأسواق المالية، فهي أحد المستثمرين

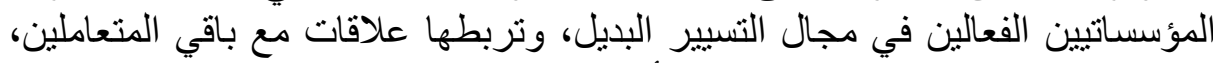

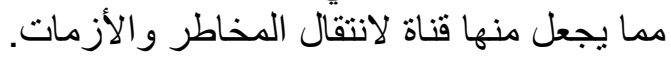

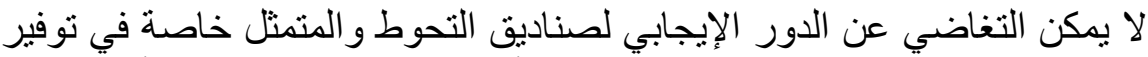
السيولة والبحث عن السعر التوازني لمختلف الأصول المالية، من جهة أخرى فإنّ التِ 


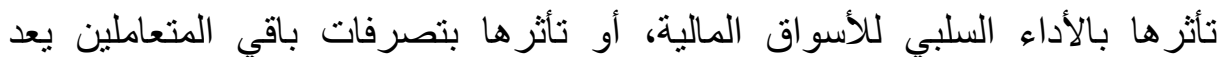

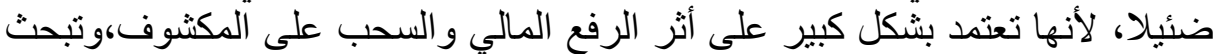

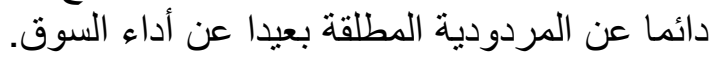

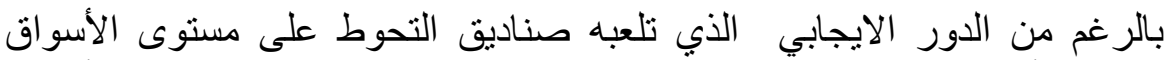

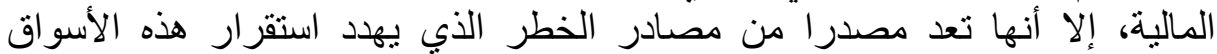

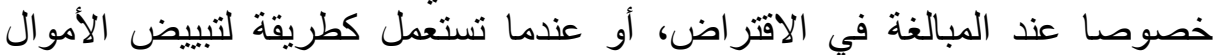
و التهرب من الضروائب.

لا تفرض على صناديق التحوط قو انين صارمة تنظم عملها، إلا أن هناك محاو لألات عديدة بشكل منفرد على مستوى البلدان لمحاولة تقنين عملها مع إعطائها الحرية التي التي التي

1. Gerard Marie Henry: 'Les hedge funds', Eyrolles, Editions d'organisation, 2008, P16.

2. Ibid.

3. Royer Cole, ''Hedge funds, transfert du risque de crédit et stabilité financière", revue de la stabilité financière, Numéro spécial, Avril $2007, \mathrm{~N}^{\circ} 10, \mathrm{P} 8$.

$$
\text { 4. - n }
$$

-Gerard Marie Henry: ''Les hedge funds", Op.cit, PP16-17.

-Andrew crockett: "Evolution et régulation des Hedge Funds", Banque de France, Revue de la stabilité financière, Numéro Special, Hedge Funds, $\mathrm{N}^{\circ} 10$, Avril 2007, PP20-21

5. Alexander Elder, "Vendre et vendre à découvert", Valor éditions, 2013, P5.

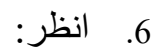

-Gerard Marie Henry: ''Les hedge funds', Op.cit, PP135-146.

-Précis sur les fonds de couverture, AIMA, Canada, 2005, PP14-23.

7. Gerard Marie Henry: 'Les hedge funds", Op.cit, P58.

8. www.captaineconomics.fr .

9. R.Boyer, 'les crises financières, Rapport du conseil d'analyse économiques, la documentation française, 2004, P85.

10. François Serge l'habitant, 'hedge funds, origine, stratégie, 
performance', Dunod, Paris, 2008, P16.

11. Eichegreen et autre, 'Démystifier les Hedge funds', Finance et développement, Volume 43, N², Juin 2006.

12. www.aljazeera.net.

13. International Monetary Fund "containing systemic risks and resorting Financial soundness "Global Financial Stability Report, Washington, April, 2008.

14. www.captaineconomics.fr

15. Markus Brunnermeir Stephan Nagel ''Hedge funds et la bulle technologique', Working paper, Université de Princeton, mai, 2002

16. Agrawal ,Fung "Liquidity provision in the convertible bond markets "disponible sur :http:// faculty research.london.edu/docs. Vu le : 09/01/2015.

17. Librairie.immateriel.fr

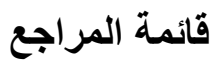

- Agrawal ,Fung "Liquidity provision in the convertible bond markets "disponible sur :http:// faculty research.london.edu/docs.

- Alexander Elder, "Vendre et vendre à découvert", Valor éditions, 2013.

- Andrew crockett: "Evolution et régulation des Hedge Funds", Banque de France, Revue de la stabilité financière, Numéro Special, Hedge Funds, N 10 , Avril 2007

- Blundel -Wi Gnall,"Structured products: Implications for financial Markets", OECD Financial Market trends, Nº3, Vol, 2007.

- Eichegreen et autre, 'Démystifier les Hedge funds', Finance et développement, Volume 43, $\mathrm{N}^{\circ} 2$, Juin 2006.

- François Serge l'habitant, 'hedge funds, origine, stratégie, performance', Dunod, Paris, 2008.

- Gerard Marie Henry: 'Les hedge funds', Eyrolles, Editions d'organisation, 2008.

- International Monetary Fund "containing systemic risks and resorting Financial soundness "Global Financial Stability Report, Washington, April, 2008.

- Librairie.immateriel.fr

- Markus Brunnermeir Stephan Nagel ''Hedge funds et la bulle technologique', Working paper, Université de Princeton, mai, 2002

- Merril Lynch, Natixis Report, 2008 . 
- Précis sur les fonds de couverture, AIMA, Canada, 2005, PP14-23.

- R.Boyer, 'les crises financières", Rapport du conseil d'analyse économiques, la documentation française, 2004.

- Roger Ferguson, David Laster," Hedge funds et risque systémique", Revue de la stabilité financière, $\mathrm{N}^{\circ} 10$, Avril, 2007.

- Royer Cole, ''Hedge funds, transfert du risque de crédit et stabilité financière", revue de la stabilité financière, Numéro spécial, Avril 2007, $\mathrm{N}^{\circ} 10$.

- www.aljazeera.net.

- www.captaineconomics.fr

- www.Fimmac. Blogs pot.com

- $\quad$ www.hedgefundresearch.com 